\title{
Mediastinitis after Cardiac Transplantation
}

\author{
Noedir A. G. Stolf, Alfredo I. Fiorelli, Fernando Bacal, Luiz F. Camargo, Edimar A. Bocchi, \\ Andréa Freitas, André Nicoletti, Daniela Meira
}

São Paulo, SP - Brazil

\begin{abstract}
Objective - Assessment of incidence and behavior of mediastinitis after cardiac transplantation.

Methods - From 1985 to 1999, 214 cardiac transplantations were performed, 12 (5.6\%) of the transplanted patients developed confirmed mediastinitis. Patient's ages ranged from 42 to 66 years (mean of $52.3 \pm 10.0$ years) and $10(83.3 \%)$ patients were males. Seven $(58.3 \%)$ patients showed sternal stability on palpation, $4(33.3 \%)$ patients had pleural empyema, and $2(16.7 \%)$ patients did not show purulent secretion draining through the wound.
\end{abstract}

Results - Staphylococcus aureus was the infectious agent identified in the wound secretion or in the mediastinum, or both, in $8(66.7 \%)$ patients. Staphylococcus epidermidis was identified in $2(16.7 \%)$ patients, Enterococcus faecalis in $1(8.3 \%)$ patient, and the cause of mediastinitis could not be determined in 1 (8.3\%) patient. Surgical treatment was performed on an emergency basis, and the extension of the débridement varied with local conditions. In 2 (16.7\%) patients, we chose to leave the surgical wound open and performed daily dressings with granulated sugar. Total sternal resection was performed in only 1 (8.3\%) patient. Out of this series, 5 (41.7\%) patients died, and the causes of death were related to the infection. Autopsy revealed persistence of mediastinitis in 1 (8.3\%) patient.

Conclusion - Promptness in diagnosing mediastinitis and precocious surgical drainage have changed the natural evolution of this disease. Nevertheless, observance of the basic precepts of prophylaxis of infection is still the best way to treat mediastinitis.

Key words: mediastinitis, cardiac transplantation, immunosuppression

Instituto do Coração do Hospital das Clínicas - FMUSP

Mailing address: Noedir A. G. Stolf - Rua João Lourenço, 386 - 04508-030 -

São Paulo, SP - Brazil
In spite of developments in cardiac transplantation, rejection and infection still constitute the major challenges for improving the results of that procedure, because they are the main causes of morbidity and mortality in the first months following transplantation ${ }^{1}$. Infections delay postoperative recovery and are present in the majority of the complications that cause transplantation failure. In other situations, infection only represents the final ordinary via of the poor evolution of the patient operated upon.

Severity and frequency of infection are directly related to the degree of immunosuppression and intraoperative conditions. Different factors, such as associated diseases, the clinical status of the recipient and of the donor, the refinement of the surgical technique, and the conditions of the surgical environment, influence the transmission of infectious agents.

Prevention is still one of the most important measures in the combat of complications of the surgical wound. However, after infection is established, precocity in its diagnosis, identification of the pathogen, and immediate application of the effective therapy contribute to solving the problem. It is worth emphasizing, however, that immunosuppression makes these patients more susceptible to invasion by microorganisms.

In conventional cardiac surgeries, the incidence of mediastinitis has been reported to range from $0.4 \%$ to $8.0 \%$, with a mortality rate of about $30 \%{ }^{2}$. In transplantation this complication is especially feared because of the resulting high mortality rate. The treatment of mediastinitis has improved in recent years because of expansion of the available resources for investigation, allowing a reduction in the time required for diagnosis and treatment ${ }^{2-4}$.

This study aims to report the experience acquired in the treatment of patients developing mediastinitis after cardiac transplantation in the last 14 years.

\section{Methods}

From March ' 85 to June '99, 214 patients underwent cardiac transplantation at the Instituto do Coração of the Hospital das Clínicas of the FMUSP. The retrospective 
analysis of this case series showed that $12(5.6 \%)$ patients developed sternal osteomyelitis or mediastinitis, or both, in the postoperative period, therefore requiring cleaning and surgical drainage.

Patients' ages ranged from 42 years to 66 years (mean of $52.3 \pm 10.0)$. Ten $(83.3 \%$ ) patients were males. In regard to the etiology of the heart disease requiring transplantation, it was ischemic in $5(41.7 \%)$ patients, idiopathic in $4(33.3 \%)$, rheumatic in 2(16.7), and Chagas' disease in 1 $(8.3 \%)$ patient.

Seven $(58.3 \%)$ patients had systemic hypertension, 4 $(33.3 \%)$ patients had previous acute myocardial infarction, $4(33.3 \%)$ experienced at least one episode of controlled infection, 4 (33.3\%) experienced pulmonary thromboembolism, $2(16.7 \%)$ showed signs of peripheral arteriopathy, and $5(41.7 \%)$ were current or previous tobacco users.

Two $(16.7 \%)$ patients had previously undergone myocardial revascularization, one of whom $(8.3 \%)$ had undergone 2 revascularizations and one pacemaker implantation. Another $(8.3 \%)$ patient had undergone replacement of the mitral valve with a bovine pericardium bioprosthesis.

Two $(16.7 \%)$ patients were in severe cardiogenic shock and, consequently, transplantation was immediately performed.

Donor's ages ranged from 37 years to 50 years (mean of $41 \pm 6.7)$. None of the donors had an active infectious or contagious disease and serum assessments for Chagas' disease, syphilis, hepatitis, and acquired immunodeficiency syndrome were negative.

Table I shows the main characteristics of the patients studied who had mediastinitis after cardiac transplantation.

In this study, we did not consider those patients with superficial infections of surgical wounds, only those with deep infection with or without spontaneous drainage of purulent secretion, involving the sternum or the mediastinum, or both, that required a reopening of the surgical incision.

The diagnosis of mediastinitis was considered posi- tive when one of the following criteria adopted by the Committee of Control of Hospital Infection at Incor was met: 1) positive culture of the mediastinal or sternal tissue or of the pericardial fluid obtained through aspiration biopsy or during surgery; 2) evidence of mediastinitis or osteomyelitis through direct examination during surgery or in the histopathological examination; 3 ) existence of one of the following parameters without any known cause: fever higher than $38.0^{\circ} \mathrm{C}$, thoracic pain, sternal instability associated with purulent drainage of the sternum or mediastinum, positive blood culture, positive culture of the material drained from the sternal or mediastinum, enlargement of the mediastinum on radiological examination, and presence of fluid collection detected through computed tomography.

Antibiotic prophylaxis after transplantation was performed in the first $2(16.7 \%)$ patients with $2 \mathrm{~g}$ of cefoxitin and $2 \mathrm{~g}$ of oxacillin by intravenous via, initiated in the anesthetic induction and repeated every 6 hours until 8 doses were completed. In the remaining patients, $1.5 \mathrm{~g}$ of cefuroxime was employed through intravenous via, started 2 hours before the surgery and repeated every 12 hours for 5 doses.

Immunosuppression and management of the rejection episodes followed the same protocol previously published ${ }^{5}$. Blood was withdrawn from donors for serum assessment of cytomegalovirus and toxoplasmosis after transplantation.

Antibiotic therapy was initially applied and modified, whenever possible, according to the sensitivity of the infectious agent and the clinical response of the patient. Empirical administration, however, was reserved for special situations of clinical severity, while identification of the pathogen was awaited.

Once the diagnosis of mediastinitis was established, the surgical treatment was immediately performed on an emergency basis. During surgery, we tried to determine the extension of the infectious process and to remove all necrotic tissue, after which we washed exhaustively the surgical wound with saline solution and povidone iodine (PVPI). In

\begin{tabular}{|c|c|c|c|c|c|c|c|}
\hline $\mathrm{N}^{\circ}$ & Sex & $\begin{array}{l}\text { Age } \\
\text { years }\end{array}$ & $\begin{array}{c}\text { Morbid } \\
\text { antecedents } \\
\text { and habits }\end{array}$ & $\begin{array}{c}\text { Period of } \\
\text { hospitalization before } \\
\text { transplantation } \\
\text { days }\end{array}$ & $\begin{array}{c}\text { Type } \\
\text { of } \\
\text { cardiomyopathy }\end{array}$ & $\begin{array}{l}\text { Previous } \\
\text { cardiac } \\
\text { surgeries }\end{array}$ & $\begin{array}{c}\text { Awaiting } \\
\text { of } \\
\text { time } \\
\text { days }\end{array}$ \\
\hline 1 & M & 55 & $\mathrm{SH}, \mathrm{AMI}$, renal lithiasis & 1 & Ischemic & - & \\
\hline 2 & M & 66 & SH, AMI, pneumonia, tobacco use & $30 *$ & Ischemic & - & 45 \\
\hline 3 & $\mathrm{~F}$ & 65 & & & Rheumatic & - & \\
\hline 4 & M & 45 & SH, UTI, PTE, pneumonia & $*$ & Idiopathic & - & 65 \\
\hline 5 & M & 40 & $\mathrm{SH}$ & 1 & Chagas' disease & - & \\
\hline 6 & $\mathrm{~F}$ & 48 & $\mathrm{SH}$ & 1 & Idiopathic & - & \\
\hline 7 & M & 42 & PTE, pneumonia & 1 & Idiopathic & - & \\
\hline 8 & M & 53 & AMI, arteriopathy, operated AbAoAn & 1 & Ischemic & (1) MR & \\
\hline 9 & M & 62 & SH, nephrectomy, tobacco use & 1 & Idiopathic & - & \\
\hline 10 & M & 45 & $\mathrm{RF}$, tobacco use & 1 & Rheumatic & (1) MVR & \\
\hline 11 & M & 65 & Pneumopathy, AMI, arteriopathy, tobacco use & $96^{*}$ & Ischemic & (2)MR, (1)PM & 96 \\
\hline 12 & M & 42 & SH, AMI, DM, tobacco use & 1 & Ischemic & - & \\
\hline
\end{tabular}


all cases, continuous irrigation with 5\% PVPI in saline solution for 5 to 7 days was maintained.

\section{Results}

Total time for transplant surgery ranged from 4 hours and 50 minutes to 12 hours, with a mean of $7.6 \pm 2.1$ hours; in 1 patient with previous cardiac surgeries this time was prolonged due to damage to the right ventricle during sternotomy. The period of use of the thoracic drains ranged from 3 to 5 days, with a mean of $3.7 \pm 0.7$ days.

Six $(50.0 \%)$ patients received intravenous pulse therapy to control acute rejection before the manifestations of mediastinitis.

At the time of diagnostic confirmation of mediastinitis, $8(66.7 \%)$ patients had a body temperature higher than $37.5^{\circ} \mathrm{C}$, and only $2(16.7 \%)$ patients did not develop leukocytosis.

Seven $(58.3 \%)$ patients showed no sternal instability on palpation, $4(33.3 \%)$ had signs of pleural empyema, and 2 $(16.7 \%)$ did not show drainage of purulent secretion through the surgical incision. One $(8.3 \%)$ patient evolved with severe thoracic pain, as an isolated manifestation $4 \mathrm{da}-$ ys before confirmation of the diagnosis of mediastinitis.

Table II shows clinical and laboratory findings of the patients at the time the diagnosis of mediastinitis was established.

Staphylococcus aureus was the infectious agent identified in the secretions of the incision, of the mediastinum, or in both, of $8(66.7 \%)$ patients; Staphylococcus epidermidis was found in $2(16.7 \%)$ patients; Enterococcus faecalis in 1 $(8.7 \%)$ patient; and in $1(8.7 \%)$ patient the cause could not be determined.

In $2(16.7 \%)$ patients, the infectious agent of mediastinitis was also isolated in the blood stream. All patients had other associated infectious foci. In $2(16.7 \%)$ patients, 2 concomitant agents were identified in the mediastinal secretion. Table III shows the distribution of the agents causing mediastinitis, the associated infections, and the antibiotic therapy employed.

Once the diagnosis of mediastinitis was established, surgical treatment was performed on an emergency basis, from the $11^{\text {th }}$ to the $52^{\text {nd }}$ day of the posttransplantation period, with a mean of 19.8 \pm 11.9 days. Extension of débridement was directly proportional to the extension of infection observed during surgery. Total sternotomy was performed only in $1(8.3 \%)$ patient due to the advanced stage of osteomyelitis. In $2(16.7 \%)$ patients, we decided to keep the surgical wound open and apply daily dressings of granulated sugar.

In $3(25.0 \%)$ patients, we had to repeat the débridement because of persistent infection. However, in case 12 (8.3\%), reoperation on the $44^{\text {th }}$ postoperative day was indicated because of persistent fever and worsening of the clinical findings; signs of active mediastinitis, however, were not found and the culture of the material collected locally was negative. Two (16.7\%) patients were readmitted because of recrudescence of infection.

In our series, $5(41.7 \%)$ patients died and their causes of death were somehow related to infection. Autopsy showed persistent mediastinitis in only 1 patient (case 8).

Table IV shows the surgical management and evolution of the patients.

\section{Discussion}

Mediastinitis substantially changes the natural evolution of the patients in the postoperative period because of high rates of morbidity and mortality. It also prolongs hospitalization and increases hospital costs ${ }^{6}$. Precocious diagnosis and prompt surgical treatment prevent infectious dissemination and its frequently devastating sequelae.

Incidence of mediastinitis in conventional cardiac surgeries has not shown a high frequency, usually lower than $1 \%$, even though during the ' $80 \mathrm{~s}$, the mortality rate attributed to this entity ranged from $14 \%$ to $47 \%{ }^{1,7}$. Recently, the

\begin{tabular}{|c|c|c|c|c|c|c|c|c|c|}
\hline \multirow[t]{3}{*}{$\mathrm{N}^{\circ}$} & \multirow{3}{*}{$\begin{array}{c}\text { Surgery duration } \\
\text { hours }\end{array}$} & \multirow{3}{*}{$\begin{array}{c}\text { Duration of } \\
\text { thoracic } \\
\text { drainage } \\
\text { days }\end{array}$} & \multirow{3}{*}{$\begin{array}{l}\text { Rejection } \\
\text { before } \\
\text { mediastinitis }\end{array}$} & \multicolumn{6}{|c|}{ *Clinical and laboratory findings } \\
\hline & & & & \multirow[t]{2}{*}{$\mathrm{T}^{\circ} \mathrm{C}$} & \multirow[t]{2}{*}{ Leukocyte counting } & \multirow[t]{2}{*}{ Sternum } & \multicolumn{3}{|c|}{ Purulent secretion } \\
\hline & & & & & & & Incision & Mediastinum & Pleura \\
\hline 1 & $4: 50$ & 3 & $3-\mathrm{B}$ & 36.5 & 14300 & unstable & No & Yes & Yes \\
\hline 2 & $6: 40$ & 4 & - & 38.0 & 16400 & stable & Yes & Yes & No \\
\hline 3 & $6: 00$ & 4 & $1-\mathrm{A}$ & 38.0 & 18900 & stable & Yes & Yes & No \\
\hline 4 & $7: 00$ & 3 & - & 37.5 & 14700 & stable & Yes & Yes & No \\
\hline 5 & $7: 30$ & 3 & $3-B$ & 37.5 & 11000 & unstable & Yes & Yes & Yes \\
\hline 6 & $4: 30$ & 3 & $3-\mathrm{A}$ & 36.5 & 8100 & stable & Yes & Yes & No \\
\hline 7 & $7: 50$ & 3 & $3-A$ & 37.5 & 15900 & unstable & Yes & Yes & No \\
\hline 8 & $7: 30$ & 5 & - & 38.0 & 12000 & stable & Yes & Yes & Yes \\
\hline 9 & 10:00 & 3 & $1-\mathrm{A}$ and $1-\mathrm{B}$ & 36.5 & 23500 & unstable & Yes & Yes & No \\
\hline 10 & 9:00 & 4 & 3-A & 36.5 & 22600 & stable & Yes & Yes & No \\
\hline 11 & $12: 00 * *$ & 4 & $1-B$ & 37.5 & 16600 & unstable & No & Yes & Yes \\
\hline 12 & 8:00 & 3 & $3-\mathrm{A}$ & 38.0 & 7300 & stable & Yes $* * *$ & Yes & No \\
\hline
\end{tabular}




\begin{tabular}{|c|c|c|c|c|}
\hline \multirow[t]{2}{*}{$\mathrm{N}^{\circ}$} & \multicolumn{2}{|c|}{ Identification of the infectious agent } & \multirow{2}{*}{$\begin{array}{l}\text { Associated } \\
\text { infection }\end{array}$} & \multirow{2}{*}{$\begin{array}{l}\text { Antibiotic therapy } \\
\text { during mediastinitis }\end{array}$} \\
\hline & Blood & Incision and/or mediastinum & & \\
\hline 1 & - & S. epidermidis & $\begin{array}{c}\text { Pneumonia } \\
\text { Oral candidiasis } \\
\text { PM site }\end{array}$ & $\begin{array}{l}\text { Cefoxitin, clindamycin, } \\
\text { cefoxitin }\end{array}$ \\
\hline 2 & - & S. aureus & $\begin{array}{l}\text { Toxoplasmosis } \\
\text { CMV, sepsis }\end{array}$ & Vancomycin, cefoxitin \\
\hline 3 & - & - & $\begin{array}{c}\text { Pneumonia } \\
\text { CMV, UTI }\end{array}$ & $\begin{array}{l}\text { Cefoxitin, clindamycin, } \\
\text { cefoxitin }\end{array}$ \\
\hline 4 & - & S. aureus & $\begin{array}{l}\text { Empyema } \\
\text { Sepsis }\end{array}$ & $\begin{array}{l}\text { Vancomycin, clindamycin, } \\
\text { ceftazidime, ceftriaxone }\end{array}$ \\
\hline 5 & S. epidermidis & S. epidermidis & $\begin{array}{c}\text { Empyema } \\
\text { Oral herpes } \\
\text { candidiasis } \\
\text { Oral }\end{array}$ & Vancomicina, cefoxitina \\
\hline 6 & - & $\begin{array}{c}\text { S. aureus } \\
\text { Enterobacter sp }\end{array}$ & $\begin{array}{l}\text { Candida } \\
\text { sepsis }\end{array}$ & $\begin{array}{l}\text { Vancomycin, fluconazole, } \\
\text { neomycin }\end{array}$ \\
\hline 7 & - & $\begin{array}{l}\text { E. faecalis } \\
\text { P. aeruginosa }\end{array}$ & Oral candidiasis & $\begin{array}{l}\text { Vancomycin, ciprofloxacin, } \\
\text { aztreonam, clindamycin }\end{array}$ \\
\hline 8 & - & S. aureus & Empyema & $\begin{array}{l}\text { Vancomycin, clindamycin, } \\
\text { ceftazidime, ceftriaxone }\end{array}$ \\
\hline 9 & - & S. aureus & Pneumonia & Vancomycin, cefuroxime \\
\hline 10 & S. aureus & S. aureus & Pneumonia & Vancomicina, cefuroxima \\
\hline 11 & - & S. aureus & Left leg & Vancomycin, ciprofloxacin \\
\hline 12 & - & S. aureus & Pneumonia & Vancomycin, clindamycin, ceftazidime \\
\hline
\end{tabular}

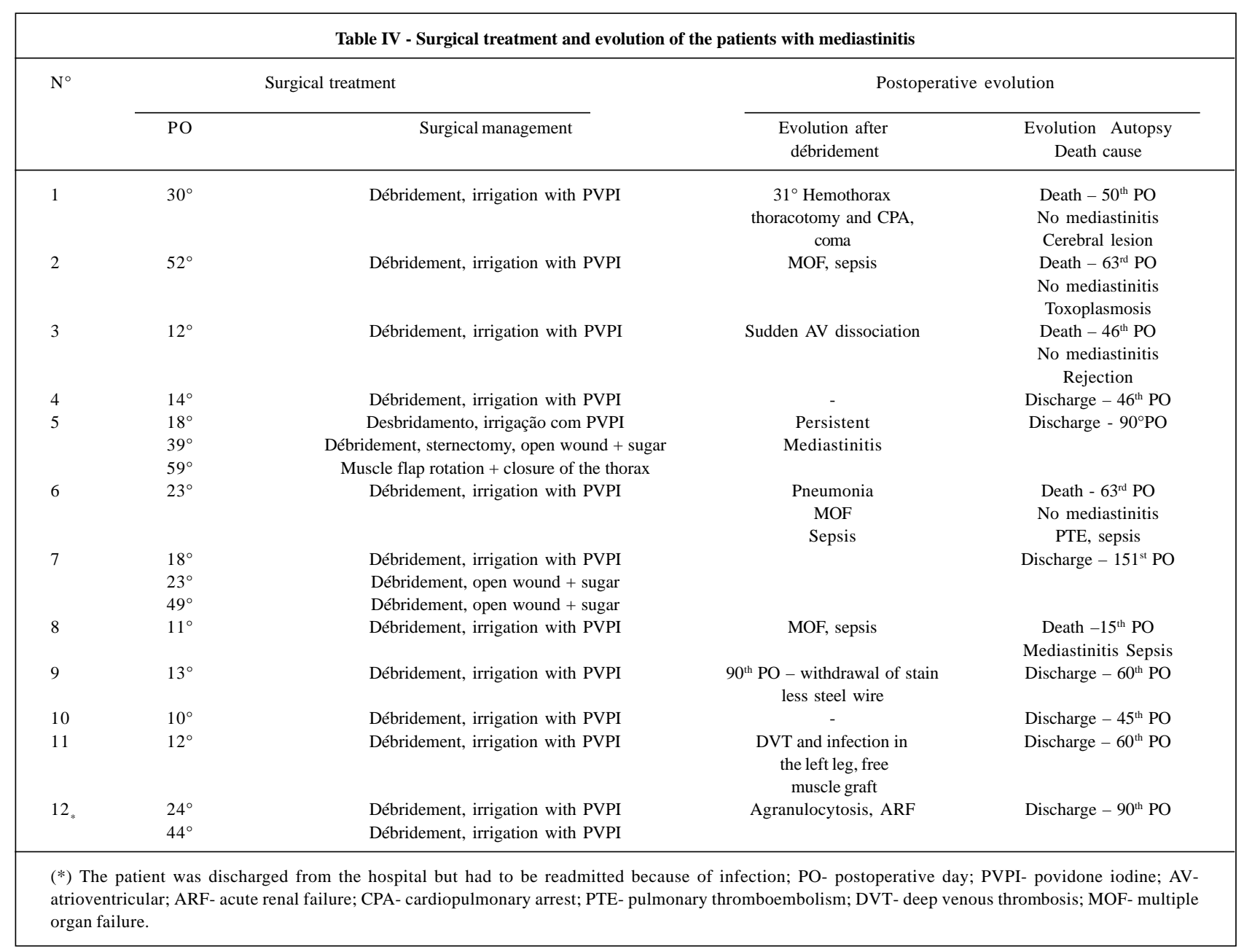


mortality rate has dropped to figures lower than $10 \%$, even in cases of cardiac transplantation ${ }^{2,8}$. In our study, the incidence of mediastinitis and its mortality confirmed the severity of that entity, which was observed by other authors ${ }^{3,6,8}$.

Grossi et $\mathrm{al}^{7}$, in an analysis of 7,949 patients undergoing cardiac operations, observed that only $0.97 \%$ of patients developed mediastinitis. They identified the following as risk factors: associated operative procedures, bleeding, low cardiac output, and prolonged mechanical ventilation.

Karwande et al $^{8}$ found mediastinitis in $2.8 \%$ of patients after cardiac transplantation and a mortality rate of $8.3 \%$. On the other hand, Albat et al ${ }^{9}$ reduced the incidence of mediastinitis after transplantation with a reduction in corticoids.

Lack of uniformity in the results found in the literature occurs, among other causes, because of the different definitions attributed to the extension of the infection in the operative wound. Complications of sternotomy vary from small sterile dehiscence to suppurative mediastinitis with severe systemic involvement. The terms mediastinitis and sternal osteomyelitis are frequently used as synonyms to refer to deep infection of the surgical wound. However, deep infections confined to the subcutaneous and muscular tissues without bone involvement, usually have a benign evolution. Considering these facts, in our series we adopted welldefined criteria of case selection to make the analysis of the results obtained easier.

Cardiac transplantation is considered a clean surgery; however, it facilitates the development of microorganisms because of the extensive surgical aggression and immunosuppression. Gram positive bacteria are the most commonly isolated agents. The incidence of Staphylococcus aureus and of Staphylococcus epidermidis in our series of patients is in accordance with the observations of other authors in whose series those pathogens accounted for more than $80 \%$ of the cases of mediastinitis ${ }^{7,10}$. Gram negative bacteria and fungi are rarely found and mixed infections are reported in about $40 \%$ of the cases ${ }^{11,12}$.

Concomitance of different pathogens observed in our series may have been facilitated by immunosuppression, which predisposes to hematogenic dissemination. Identification of Toxoplasma gondii in the mediastinum at autopsy of one patient was attributed to the extensive dissemination of toxoplasmosis, and it was not considered the causative agent of the mediastinitis.

The beginning of mediastinitis and its sequential evolution are not easily characterized because different factors influence the pathogenesis of that entity. Inappropriate drainage of the mediastinum resulting in maintenance of serosanguineous collections in the retrosternal space predisposes to colonization and propagation of microorganisms. In other situations, bone instability and skin disruption are the factors predisposing to infection. Usually, in the precocious phases, osteomyelitis is confined to local tissues and sternal instability, which appears in a few days, reflects the advanced stage of the infection. Chronic mediastinitis that occurs a few weeks after operation is characterized by fistulae or circumscribed collections and provides an opportunity for treatment with more satisfactory results ${ }^{13}$.

This latter observation seems to have significantly influenced the evolution of the patients studied because control of the infection was easier in those patients in whom the mediastinitis appeared in the $2^{\text {nd }}$ or $3^{\text {rd }}$ week after transplantation. In this subgroup of patients, other factors, such as preexisting clinical conditions, precocity of reintervention, intensity and virulence of the aggressive agent, may have positively influenced and helped to block the infectious process.

Mediastinitis maintained its local activity in only $8.3 \%$ of the patients; in the remaining patients, remission occurred, even in those who eventually died, in whom the autopsy identified organization of the process. This suggests that the treatment applied was effective in subduing the local infection.

The major risk factors for the development of infections in the mediastinum are the following: tobacco use, pneumopathies, prolonged preoperative hospital stay, inappropriate preparation of the skin for surgery, bleedings, reoperations, prolonged intubation, and immunosuppression ${ }^{1,2,7}$. Identification of these factors and the refinement of the operative technique constitute important tools in the prevention of postoperative infections. Surgical precautions range from sternotomy with adequate hemostasis to the rational use of the electrocautery and bone wax ${ }^{10,11}$.

Classical signs and symptoms of acute infection usually found in mediastinitis may be masked by the thoracic pain proper of the postoperative period or other associated infections. Suppuration through the incision and sternal instability that characterize mediastinitis do not always appear as the first manifestations of infection, as occurred in $83.3 \%$ and $41.6 \%$, respectively, of the cases studied. In different experiences, those manifestations have been reported with an incidence of up to $90 \%{ }^{7,8}$.

In the present study, the low incidence of sternal instability may have resulted from the precocity of the surgical treatment, which did not allow time for bone involvement.

Only 1 patient had severe thoracic pain as an isolated manifestation for 4 days, before confirmation of the clinical finding of mediastinitis could be established. Fever and leukocytosis, which are frequently found in infectious processes, were present in the initial phase of the diagnosis of mediastinitis in $66.7 \%$ and $83.3 \%$ of the patients, respectively.

Daily clinical carefull follow-up provides the best means for identifying mediastinitis because laboratory investigation is not specific and only supports the clinical suspicion. Blood cultures were positive in $16.7 \%$ of the patients studied. Kohman et $\mathrm{al}^{12}$ found bacteremia in $59.2 \%$ of the patients developing mediastinitis after myocardial revascularization. Immunosuppression certainly changes the natural inflammatory response observed in mediastinitis.

Chest X-ray rarely helps the diagnosis of mediastinitis in its initial phase, providing more important information for the evolutional follow-up of the pulmonary pattern. Serial 
analysis of echocardiography and computed tomography provides substantial information concerning the appearance of pericardial or retrosternal collections because transplantation significantly modifies mediastinal anatomy ${ }^{3}$. It should be emphasized that more important than isolated analysis of a single examination is the daily clinical observation associated with clinical and laboratory findings.

The treatment of mediastinitis as applied in this study varies from a very simple débridement, partial or total resection of the sternum, to more complex procedures with rotation of muscle flaps ${ }^{7,9,13}$. Isolated antibiotic therapy and surgical cleaning were not used in any situation and are not accepted in the current practice.

The technique of débridement and primary closure of the sternum with continuous antibiotic irrigation of the mediastinum was initially and successfully described by Shumacker and Mandelbaum ${ }^{14}$ in 1963 in the treatment of mediastinitis caused by Staphylococcus after cardiac surgery. Irrigation with antibiotics or $0.5 \%$ iodine solution have significantly reduced mortality rates due to mediastinitis, even though morbidity and mortality rates are still high in that affliction ${ }^{15}$. Irrigation in its different forms aims to mechanically clean and remove necrotic material.

Use of muscle flaps or epiploon has been controversial, and surgical aggression and opportunities for using this technique should be considered ${ }^{15-17}$. In our patients, the orientation adopted has always been directed at an initial débridement of necrotic tissues, multiple drainage of the mediastinum and thoracic cavity, primary closure of the sternum and maintenance of continuous irrigation with a solution of $0.5 \%$ povidone iodine for 5 to 7 days.

The surgical wound was maintained open in $16.7 \%$ of the patients. These were special situations in which failure in the primary treatment or extensive sternal involvement occurred requiring wide bone resections. These patients were removed from the prolonged mechanical ventilation after recovery of the general clinical condition and the surgical wounds were kept open. This favors cleaning and drainage of the secretions, avoids dissemination of the infection and helps healing. Compressing the thorax with bandages allows approximation of the sternum resulting in wound healing. Rotation of the rectus abdominis muscle was employed in one case with total sternal resection.

In conclusion, treatment of mediastinitis is still a major challenge for the medical team because that entity drastically changes the postoperative evolution of cardiac transplantation and may leave sequelae. The early diagnosis and precocious reintervention have modified the natural evolution of that process. However, observation of the basic precepts of infectious prophylaxis still constitutes the best way to treat mediastinitis.

\section{References}

1. Maria R, Minoli L, Parolini M, et al. Prognostic determinants of six-month morbidity and mortality in heart transplant recipients. The Italian Study Group on Infection in Heart Transplantation. J Heart Lung Transplant 1996; 15:124-35.

2. Culliford AT, Cunningham JN,ZeffRH, Isom OW, TeikoP, SpencerFC. Sternal and costchondral infections following open-heart surgery. A review of 2594 cases. J Thorac Cardiovasc Surg 1976; 72: 714-26.

3. MisawaY, Fuse K, Hasegawa T. Infections mediastinitis after cardiac operations: computed tomographic findings. Ann Thorac Surg 1998; 65: 622-4.

4. Quirce R, Serano J, Arnal C, Banzo I, Carril JM. Detection of mediastinitis after heart transplantation by gallium-67 scintigraphy. J Nucl Med 1991; 32: 860-1.

5. Fiorelli AI, Stolf NAG. Cuidados no pós-operatório do transplante cardíaco. Rev Bras Cir Cardiovasc 1996; 11: 30-8.

6. ReeceIJ, Painvin A, Chandler LB, et al. Infection after cardiac transplantation: treatment and prognosis. Texas Heart Institute J 1984; 11: 32-7.

7. Grossi EA, Culliford AT, Krieger KH, et al. A survey of 77 major infectious complications of median sternotomy: a review of 7949 consecutive operative procedures. Ann Thorac Surg 1985; 40: 214-23.

8. Karwande SV, Renlund DG, Olsen SL, et al. Mediastinitis in heart transplantation. Ann Thorac Surg 1992; 54: 1039-45.

9. Albat B, Trinh Duc P, Boulfroy D, Picard E, Wintrebert P, Thevenet A. Mediasti- nitis in heart transplant recipients: successful treatment by closed local irrigation. Cardiovasc Surg 1993; 1: 657-9.

10. Demmy TL, Park SB, Liebler GA, et al. Recent experience with major sternal wound complications. Ann Thorac Surg 1990; 49: 458-62.

11. Sarr MG, Gott VL, Townsend TR. Mediastinal infection after cardiac surgery. Ann Thorac Surg 1984; 38: 415-23.

12. Kohman LJ, Coleman MJ, Parker FB. Bacteremia and sternal infection after coronary artery bypass grafting. Ann Thorac Surg 1990; 49: 454-7.

13. Majure JA, Albin RE, O'Donnell RS, Arganese TJ. Reconstruction of the infected median sternotomy wound. Ann Thorac Surg 1986; 42: 9-12.

14. Shumacker HB, Mandelbaum I. Continuous antibiotic irrigation in the treatment of infection. Arch Surg 1963; 86: 384-7.

15. Acinapura AJ, Godfrey N, Romita M, et al. Surgical management of infected median sternotomy: closed irrigation vs. Muscle flaps. J Cardiovasc Surg 1985; 26:443-6.

16. Scully HE, Leclerc Y, Martin RD, et al. Comparison between antibiotic irrigation and mobilization of pectoral muscle flaps in treatment of deep sternal infection. J Thorac Cardiovasc Surg 1985; 90: 523-31.

17. Pervosti LG, Subramainian A, Rothaus KO, Dineen P. A comparison of the open and closed methods in the initial treatment of sternal wound infections. JCardiovasc Surg 1989; 30: 757-63. 